\title{
DIAGNÓSTICO FITOSANTTARIO Y RECOMENDACIONES DE MANEJO AGROECOLÓGICO DE PLAGAS EN COMUNAS DE LAS PROVINCIAS DE GUAYAS YSANTA ELENA
}

\author{
Rigoberto García Batista 1, Libertad Machado López 1, Dolores Piñón Gómez ${ }^{2}$ \\ Alberto Gómez Ruiz ${ }^{2}$, Miguel Ventura Cruz ${ }^{2}$ \\ Universidad Técnica de Machala (Ecuador) \\ Instituto de Investigaciones de la Caña de Azúcar (Cuba) ${ }^{2}$ \\ rmgarcia@utmachal.edu.ec ${ }^{1}$
}

Cómo citar este artículo: García, R., Machado, L., Piñón, D., Gómez, A. y Ventura, M. (2015) Diagnóstico fitosanitario y recomendaciones de manejo agroecológico de plagas en comunas de las provincias de Guayas y Santa Elena. CUMBRES, Revista Científica 1(1), $17-22$

\section{RESUMEN}

El presente estudio se desarrolló en 10 Comunas ubicadas en las provincias de Guayas y Santa Elena, en el marco del Proyecto PIDAASSE, esto conllevó la visita y recorrido por las diferentes parcelas de los comuneros incorporados al proyecto, y levantar información sobre los cultivos que desarrollaban en las mismas, lo que propiciaría desarrollar como objetivos de este trabajo la valoración del manejo agrícola que recibían los cultivos, identificación de las principales plagas, el establecimiento de un Manejo Agroecológico de Plagas, MAP, con la implementación de diferentes esquemas según los cultivos a desarrollar.

La metodología utilizada en el estudio es la recomendada por el INICA y su Departamento de Sanidad Vegetal, se realizó entrevistas a los comuneros y tener más conocimientos de la situación en sus áreas de producción. Como resultados del Diagnóstico se presentaron diferentes Esquemas generales para la implementación de MAP en cada uno de los siguientes cultivos: yuca, plátano, hortalizas, fréjol, maíz, cucurbitáceas y otros.

Palabras clave: Identificación de plagas, daños de plagas, MAP.

\begin{abstract}
This study was carried out in ten communes in Guayas and Santa Elena provinces in the period between January and May 2011, under the PIDAASSE Project, which included the visit and tour of the various plots of the project's villagers with the objective to build information about what cultivations are developed in the sector, and what are the plant damages present in the area, either by pests or diseases, thereby facilitating the development objectives such as the assessment of agricultural management in crops, identifying key pests, establishment an agro-ecological pest management, MAP, with the implementation of different schemes depending on the crops to develop.
\end{abstract}

The methodology used in the study was recommended by the INICA and Plant Health Department, where sampling areas of different crops production was performed, evaluating the damages and determining the causative agents. Also the paper shows interviews to the villagers to have more knowledge of the situation in their areas of production. As diagnostic's result the paper shows different schemes for the implementation of MAP in each of the following crops: cassava, plantain, vegetables, beans, corn, cucurbits and other.

Keywords: Identification of pests, pest damage, MAP. 


\section{INTRODUCCIÓN}

El presente estudio se desarrolló en 10 Comunas ubicadas en las provincias de Guayas y Santa Elena en el periodo comprendido entre enero y mayo de 2011, en el marco del Proyecto PIDAASSE, esto conllevó la visita y recorrido por las diferentes parcelas de los comuneros incorporados al Proyecto, levantar información sobre los cultivos que desarrollaban en las mismas y las afectaciones fitosanitaria presentes, ya sea por plagas o enfermedades, lo que propiciaría desarrollar como objetivos de este trabajo la valoración del manejo agrícola que recibían los cultivos, identificación de las principales plagas, el establecimiento de un Manejo Agroecológico de Plagas, MAP, con la implementación de diferentes esquemas según los cultivos a desarrollar.

\section{Diagnóstico de las áreas agrícolas en las comunas es- tudiadas}

Las plagas y el desconocimiento en su manejo pueden afectar los rendimientos y la calidad de los cultivos (García et al., 2003),. El muestreo realizado en las diferentes comunas como parte del Diagnóstico nos permitió detectar los insectos plagas y enfermedades detectados en los diferentes cultivos y su porcentaje promedio de incidencia (PIP), lo que se muestra en el Cuadro 1. (Relación de insectos plagas y enfermedades detectados en los diferentes cultivos y su porcentaje promedio de incidencia PIP).

Cuadro 1. Relación de insectos plagas y enfermedades detectados en los diferentes cultivos y su porcentaje promedio de incidencia (PIP)

\begin{tabular}{|l|c|l|c|}
\hline \multicolumn{1}{|c|}{ Plagas del Pimiento } & PIP (\%) & \multicolumn{1}{|c|}{ Plagas del cacao } & PIP (\%) \\
\hline Bemisia tabaci & 42,69 & Áfidos (Aphys gossypii, & 33.2 \\
\hline Spodoptera sp. & 33,92 & Toxoptera aurantii) & 13,4 \\
\hline Áfidos & 26,87 & $\begin{array}{l}\text { Barrenadores del tallo } \\
\text { (Cerambicidae Xyleborus confusus) }\end{array}$ & 23.4 \\
\hline Ácaros & 23,14 & Moniliasis (Monilia roreri), & 21,5 \\
\hline $\begin{array}{l}\text { Escarabajo del follaje } \\
\text { (Diabotrica decolor) }\end{array}$ & 21,28 & $\begin{array}{l}\text { Mal de machete (Ceratocystis } \\
\text { fimbriata), }\end{array}$ & 12,5 \\
\hline $\begin{array}{l}\text { Marchitamiento } \\
\text { por Fusarium oxysporum }\end{array}$ & 18,68 & Mazorca negra (Phytophtora spp.) & 14,4 \\
\hline $\begin{array}{l}\text { Tizón del fruto } \\
\text { por Phytopthora }\end{array}$ & 24,23 & Salivazos & 20.8 \\
\hline Virosis & 14,54 & Ácaros & 23,6 \\
\hline $\begin{array}{l}\text { Fusariosis (Fusarium } \\
\text { oxysporum }\end{array}$ & 15,89 & Chinches & 12,8 \\
\hline
\end{tabular}

\begin{tabular}{|l|c|}
\hline Plagas en el maíz, Sorgo & PIP (\%) \\
\hline $\begin{array}{l}\text { Gusano cogollero } \\
\text { (Spodoptera frugiperda) }\end{array}$ & 48,5 \\
\hline Pulgones & 30,9 \\
\hline Ácaros & 33,4 \\
\hline Rhopalosiphum maidis & 25,8 \\
\hline $\begin{array}{l}\text { Virosis (virus del } \\
\text { mosaico ) }\end{array}$ & 11,2 \\
\hline
\end{tabular}

\begin{tabular}{|l|l|}
\hline $\begin{array}{c}\text { Plagas en el banano y el } \\
\text { plátano }\end{array}$ & PIP (\%) \\
\hline Thrips spp & 29,8 \\
\hline $\begin{array}{l}\text { Sigatoka negra } \\
\text { (Mycosphaerella fijiensis) }\end{array}$ & 12,9 \\
\hline $\begin{array}{l}\text { Picudo negro (Cosmopolites } \\
\text { sordius G.) }\end{array}$ & 10,9 \\
\hline
\end{tabular}

\begin{tabular}{|l|c|}
\hline \multicolumn{1}{|c|}{ Plagas en la Maracuyá } & PIP (\%) \\
\hline Gusano mono & 11,2 \\
\hline Minador & 12,4 \\
\hline Antracnosis (Colletotrichum sp.), & 13,2 \\
\hline $\begin{array}{l}\text { Pudrición de la fruta } \\
\text { (Phytophthora sp.) }\end{array}$ & 13,2 \\
\hline
\end{tabular}

Elaborado por: (García et al., 2015) 
Teniendo en cuenta el componente de plagas y enfermedades la cualidad de la tierra se clasificó de la siguiente forma, Cuadro 2. (Clasificación del componente de plagas y enfermedades según la cualidad de la tierra).
Cuadro 2. Clasificación del componente de plagas y enfermedades según la cualidad de la tierra

\begin{tabular}{|l|l|ll|l|l|}
\hline Cualidad & \multicolumn{1}{|c|}{ A1 } & \multicolumn{1}{|c|}{ A2 } & \multicolumn{1}{|c|}{ A3 } & \multicolumn{1}{c|}{ No apto } \\
\hline PIP & Menor que $15 \%$ & Entre el & $15-$ & Mayor que $30-$ & Mayor del \\
& & $30 \%$ & & $40 \%$ & $40 \%$ \\
\hline
\end{tabular}

Los valores establecidos Cuadro 3. (Valores establecidos acorde a la incidencia de plagas), acorde a la incidencia de plagas son los siguientes:
Cuadro 3. Valores establecidos acorde a la incidencia de plagas

\begin{tabular}{|c|c|}
\hline Valor establecido & Característica \\
\hline 1 & PIP mayor del $30 \%$ \\
\hline 5 & PIP entre el $15-30 \%$ \\
\hline 10 & Menor del $15 \%$ \\
\hline
\end{tabular}

Figura 1. Maíz afectado por ataque de pulgones, Áfidos y cogollero Spodoptera frugiperda)

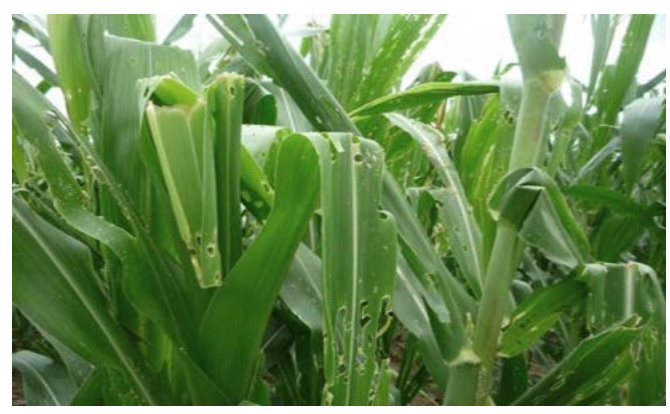

Elaborado por: (García et al., 2015)

Como se observa el mayor porcentaje de las plagas que afectan a los cultivos se encuentran en el intervalo definido para la categoría A2 de los suelos. En el caso de la incidencia de pulgones y ácaros en Pimiento y Spodoptera frugiperda en maíz y sorgo el porcentaje determinado clasifica a los suelos en la categoría A3., Cuadros 1,2 y 3.

Por lo anterior en la selección de los híbridos o cultivares a plantar en las nuevas áreas agrícolas, se deberá tener en cuenta su resistencia a las plagas relacionadas para cada uno de los cultivos, así como evaluar las posibilidades de implementar un programa de protección fitosanitaria que permita el manejo agroecológico de plagas en las áreas productivas y mantener los niveles de daño por debajo de los umbrales económicos lo que determinará el éxito de los cultivos.

\section{Estrategias para el MAP, (manejo agroecológico de plagas) enmarcado en la actividad de proyección de los cultivos a plantar}

El manejo agroecológico de plagas comprende varias acciones, desde la preparación del suelo, la selección del material de siembra, el desarrollo de metodologías para el muestreo y la señalización de agentes nocivos como base para la aplicación de plaguicidas, fundamentalmente biológicos, el control etológico (implementación de trampas), conocimiento y evaluación de las rutas libres de mosca de la fruta, el diseño de plantación atendiendo a la diversidad florística, la interacción con los diferentes subsistemas agrícolas, las plagas cuarentena das, el cumplimiento de los índices sanitarios para el consumo nacional y la exportación entre otros. En esta etapa fueron recomendados y analizados diferentes variantes para la rotación e intercalamiento de los cultivos, así como la inclusión de trampas, barreras vivas y plantas repelentes.

Establecimiento de trampas para mosca de la fruta y otras plagas como parte de la implementación del MAP

El MAP son procesos que se efectúan en la siembra de cultivos en los diferentes agroecosistemas debido a que siempre tiene aparejada la llegada de algunos agentes de deterioro (insectos, ácaros, etc.) los cuales se van a presentar en menor o mayor medida, según hayan sido las precauciones y el manejo del hábitat hecho por el agricultor. 
Fue analizada la cobertura a las áreas de cultivos de la ruta actual para el monitoreo de la mosca de la fruta Anastrepha grandis (Díptera: Tephritidae) requisito fundamental para mantener el reconocimiento oficial e internacional de las exportaciones de productos en cuanto a niveles de afectación por este insecto. Figura 2.

\section{Distribución de trampas para el manejo agroecoló- gico de plagas}

Considerando los resultados del diagnóstico y valorando las trampas ubicadas en la ruta de la mosca blanca, se realizó una nueva distribución de estas y garantizar un mayor cubrimiento del área a cultivar. Cuadro 4. (Distribución de trampas para el manejo agroecológico de plagas en cultivos perennes).

Nota: En ciclo corto instalamos una (1) trampa Mcphail por hectárea y una (1) Jackson cada cinco (5) hectáreas. Cuadro 5. (Distribución de trampas para el MAP en cultivos de ciclo corto).

El método de trampas funciona bien asociado a otros procedimientos de control y consiste en aprovechar la cromotaxis, o lo que es lo mismo, la influencia atrayente que ejercen los colores sobre algunas plagas de insectos y utilizar este conocimiento como táctica de control. Los colores utilizados son el amarillo, azul y blanco y el método consiste en colocar recipientes, secciones de plástico, madera e incluso trozos de yaguas con estos colores (Brechelt, 2004)
La recomendación de esta estrategia de manejo, como base de un MAP, es hacer un reordenamiento de las áreas de producción, de modo de alcanzar una mayor estabilidad ecológica. Este reordenamiento, en la búsqueda de un medio ambiente en equilibrio, practicando la coexistencia con la naturaleza, tratando de estimular sus sistemas y potenciar sus capacidades. Se trata de maximizar la capacidad productiva a través de la biodiversidad; proporcionando condiciones óptimas a la fertilidad natural, favoreciendo la vida del suelo para lograr una producción eficiente, sana y sostenible, (www.rapaluruguay.org). Para garantizar esta estrategia se confeccionaron 9 esquemas de MAP generales por grupos de cultivos, los que se describen a continuación.

Para controlar antracnosis y otras enfermedades foliares, se deberán aplicar los fungicidas específicos.

\section{Esquema 1. Aplicable a todos los cultivos}

Seleccionar variedades o híbridos resistentes a las enfermedades que están afectando a los cultivos y cuya presencia ha sido corroborada por el Proyecto PIDAASSE.

Las áreas de cultivo y sus alrededores deben estar libres de plantas indeseables (malezas), eliminando las que constituyen focos de insectos dañinos y enfermedades.

Mantener un chequeo sistemático del nivel de infestación por nemátodos y aplicar las medidas recomen-

Cuadro 4. Distribución de trampas para el manejo agroecológico de plagas en cultivos perennes

\begin{tabular}{|l|l|c|c|c|c|c|}
\hline \multirow{2}{*}{ Cultivo } & \multicolumn{1}{|c|}{ Plagas } & \multicolumn{5}{c|}{ Trampas/ha } \\
\cline { 3 - 7 } Guayaba & $\begin{array}{l}\text { Moscas de las frutas y } \\
\text { Pulgón }\end{array}$ & 1 & 1 & 4 & 0 & 0 \\
\hline Cacao & $\begin{array}{l}\text { Pulgón, Barrenador } \\
\text { Trips, Picudo negro, } \\
\text { Escátana y Áfidos }\end{array}$ & 0 & 0 & 4 & 4 & 0 \\
\hline Maracuyá & $\begin{array}{l}\text { Mosca de la fruta, Ácaros } \\
\text { Trips y Perforador de hojas } \\
\text { Gusano mono }\end{array}$ & 1 & 1 & 0 & 4 & 0 \\
\hline
\end{tabular}

Cuadro 5. Distribución de trampas para el MAP en cultivos de ciclo corto

\begin{tabular}{|l|l|c|c|c|c|c|}
\hline Cultivo & Plaga & Mcphail & Jackson & Amarilla & Azul & Otros \\
\hline Maíz & $\begin{array}{l}\text { Cogollero, } \\
\text { Pulgón y } \\
\text { ácaros }\end{array}$ & 0 & 0 & 4 & 4 & 0 \\
\hline Sorgo & $\begin{array}{l}\text { Cogollero, } \\
\text { Pulgón y } \\
\text { ácaros }\end{array}$ & 0 & 0 & 4 & 4 & 0 \\
\hline
\end{tabular}


dadas

Se limitará la entrada de personal ajeno, no autorizado, a las áreas de producción.

Garantizar que las semillas sean de alta calidad, validadas por una certificación.

En el caso de utilizarse posturas para la siembra, éstas deberán estar completamente sanas.

Planificar la siembra según el calendario óptimo, teniendo en cuenta el programa de rotación de cultivos y evitar la colindancia con especies y variedades afines. Mantener un adecuado sistema de drenaje para evitar los encharcamientos y exceso de humedad.

Eliminar con rapidez los residuos de cosecha una vez concluida.

- Se prohíbe fumar y manipular las plantas sin previo lavado de manos, fundamentalmente de tomate, pimiento, ají y otras susceptibles al ataque de virus del mosaico de tabaco (TMV).

- Colocar trampas amarillas, azules, blancas y de luz para capturar insectos dañinos.

- Sembrar barreras de plantas repelentes y trampas para disminuir la incidencia de plagas en los cultivos.

Aplicar de forma preventiva y sistemática medios de control biológico que se recomienden acorde a los índices de infestación y de señal evaluados por el sistema fitosanitario de PIDAASSE y proteger los organismos biológicos naturales.

- Selección negativa de plantas atacadas por virus.

- Rotación de cultivos y medidas de cuarentena, en especial para virus, bacterias y nemátodos.

\section{Esquema 2. Yuca y malanga}

Exponer crisálidas de la primavera y pupas de la centella a sus enemigos naturales mediante una buena preparación del suelo.

- No sembrar áreas que colinden con campos del cultivo de avanzado desarrollo.

- Mantener el cultivo y sus alrededores libres de plantas indeseables, particularmente de euforbiáceas silvestres.

Liberaciones de diferentes combinaciones de medios biológicos en dosis preventivas y curativas en caso de elevación de los índices de infestación.

\section{Esquema 3. Banano y Plátano}

Efectuar siembras en terrenos libres de nemátodos. Análisis nematológico del suelo y de la materia orgánica, plantas indicadoras de niveles de nemátodos en suelo.

Mantenimiento de barbechos sin malezas.
- Buena selección de los cultivos o especies de cobertura o asociados en los sistemas de rotación de cultivos intercalados.

Uso de plantas - trampa.

- Liberaciones de medios biológicos preventivos y curativos acorde a cada tipo de plaga y el estado fenológico del cultivo. Químicos en caso de que las infestaciones sobrepasen el umbral económico de daño.

- Proteger los racimos de frutos con fundas de Nylon.

\section{Esquema 4. Hortalizas}

- Sembrar barreras de maíz o sorgo 20 días antes de la plantación.

- Se prohíbe la colindancia entre áreas de tomate con más de 20 días de diferencia en la plantación.

- Se autorizan las siembras colindantes posteriores a las del tomate si se sitúa una barrera divisoria de maíz o sorgo entre ambos de no menos de 10 surcos y que los mismos, antes de la siembra del cultivo hospedante, alcancen los $20 \mathrm{~cm}$.

- Tratar el suelo y las posturas con el producto biológico indicado antes de la plantación.

- Sembrar en bloques y avanzar en dirección contraria a la de los vientos predominantes.

- Monitoreo sistemático y aplicación de medidas preventivas y curativas.

- Selección negativa de plantas virosas mientras no estén fructificadas.

- Aplicaciones biológicas y/o químicas sustentadas en la ausencia o presencia de virosis e indicadores fitosanitarios.

\section{Esquema 5. Cebolla}

- Desinfección del suelo y bulbos con medios biológicos antes de plantar

Monitoreo cada 7 días.

- Preservar los enemigos naturales; prohibido emplear químicos.

- Aplicación de los medios biológicos correspondientes.

\section{Esquema 6. Cucurbitáceas}

- Análisis de los suelos por plantas indicadoras para la detección de nemátodos del género Meloidogyne.

- Manejar la preparación de suelo en función de los niveles de afectación de nemátodos del género Meloidogyne.

Emplear materia orgánica libre de nemátodos.

- Evitar colindancia con áreas infestadas de plagas, especialmente con Thrips palmi. 
- Evitar el empleo de medios químicos para preservar los enemigos naturales y durante la floración prohibirlos para garantizar la polinización por las abejas. Resulta muy favorable en estos cultivos hacer intercalamientos, en especial de maíz y sorgo.

\section{Esquema 7. Gramíneas (Maíz y Sorgo)}

- Preservar los enemigos naturales; en especial los biorreguladores de Spodoptera frugiperda.

- Para el control de huevos de la palomilla se empleará el medio biológico correspondiente.

- Se tendrá en cuenta la presencia de larvas de esta plaga para emplear bacterias o nemátodos entomopatógenos.

- Con la presencia de pupas se realizarán liberaciones de bioproductos específicos de esta fase de la plaga.

\section{Esquema 8. Leguminosas (Fréjol)}

- En este cultivo es obligatorio usar intercalamientos de maíz o sorgo, es recomendable, además, hacer barreras de estos propios cultivos y hay que evitar la colindancia con tomate.

- Aplicar preventivamente los productos biológicos y trampas fitosanitarias, así como las combinaciones establecidas para el manejo de la mosca blanca y el thrips.

- Utilizar tratamientos de biopreparados específicos para reducir la incidencia de enfermedades fungosas en el área foliar.

- Instalación las trampas de color (blancas, amarillas, azules) en diferentes puntos del campo.

- Bajo ningún concepto se pueden repetir siembras del mismo cultivo en ciclos sucesivos

\section{Esquema 9. Frutales}

- Mantener un estricto control sobre los niveles de mosca de la fruta y otras plagas objeto de cuarentena

- Seleccionar las áreas alejadas de plantas hospederas de mosca blanca y otras plagas afines.

- Eliminación de plantas hospederas en un radio de acción no menor de 100 metros.

Preservar los enemigos naturales

- Contra áfidos y mosca blanca se emplearán biopreparados en cuanto se emita la señal fitosanitaria.

- Mantener la gama de aplicaciones de productos biológicos diseñado para estos cultivos para las diferentes fases de su desarrollo

- Saneamiento y destrucción de residuos en caso de aparecer virosis. Eliminación de vectores
- Para controlar antracnosis y otras enfermedades foliares, se deberán aplicar los fungicidas específicos.

\section{CONCLUSIONES}

1. Los resultados del diagnóstico apuntan hacia la necesidad de proponer un Programa Fitosanitario que garantice la protección de los cultivos a implementar en el proyecto.

2. Implementar los 9 esquemas descritos para la implementación del MAP en las áreas de las Comunas en estudio en las provincias de Guayas y Santa Elena

3. Realizar acciones fitosanitarias para el control de las plagas de manera amigable con el medio ambiente como las propuestas en el proyecto.

\section{REFERENCIAS BIBLIOGRÁFICAS}

- Brechelt, A. (2004). Manejo Ecológico de Plagas y Enfermedades. Disponible en Internet: www.visionagroecologica.blogspot.com.

- Maturana, E. El manejo ecológico de plagas y enfermedades, tiene como elemento central el reordenamiento de las unidades de producción predial. Corporación CIAL: Revista Enlace (Nº 59 y 60).

- García, R., Acosta, O., Santos, M., Jiménez, J., Ariosa, M., et al., y Armas, J. (2003). Manejo de plagas. Disponible en Internet: www.monografias.com/trabajos47/manejo-plagas/manejo-plagas.shtml

- Manejo Agroecológico de Plagas, La Habana, Cuba: Laboratorio Provincial de Sanidad Vegetal de Sancti Spiritus. (www.ecured.cu /index.php).

- Rodríguez, A. Investigaciones Fundamentales en Agricultura Tropical. (INIFAT). La Habana, Cuba: Fuente: Revista Enlace No 59 y 60. www.rapaluruguay.org/organicos/articulos/manejo.html. 